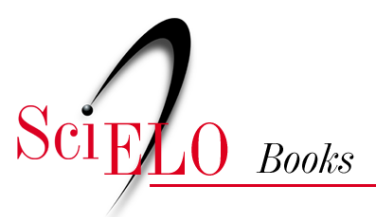

\author{
6 - Módulo \\ observação de Práticas Médicas \\ Julieta Freitas Ramalho da Silva \\ Paulo Schor \\ Maysa Seabra Cendoroglo \\ Rudolf Wechsler
}

SILVA, JFR., et al. Módulo: observação de práticas médicas. In PUCCINI, RF., SAMPAIO, LO., and BATISTA, NA., orgs. A formação médica na Unifesp: excelência e compromisso social [online]. São Paulo: Editora Unifesp, 2008. pp. 161-189. ISBN 978-85-61673-66-6. Available from SciELO Books <http://books.scielo.org>.

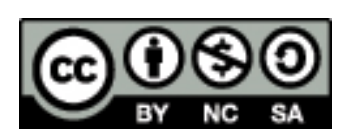

All the contents of this work, except where otherwise noted, is licensed under a Creative Commons Attribution-Non Commercial-ShareAlike 3.0 Unported.

Todo o conteúdo deste trabalho, exceto quando houver ressalva, é publicado sob a licença Creative Commons Atribuição Uso Não Comercial - Partilha nos Mesmos Termos 3.0 Não adaptada.

Todo el contenido de esta obra, excepto donde se indique lo contrario, está bajo licencia de la licencia Creative Commons Reconocimento-NoComercial-CompartirIgual 3.0 Unported. 


\title{
6 \\ Módulo: Observação de Práticas Médicas
}

\author{
Julieta Freitas Ramalho da Silva, \\ Paulo Schor, Maysa Seabra Cendoroglo \\ e Rudolf Wechsler
}

INTRODUÇÃO

O Módulo Observação de Práticas Médicas (OPM) constui uma inovação no currículo médico da Escola Paulista de Medicina (EPM), Universidade Federal de São Paulo (Unifesp) e foi implantado em 2003. Como o próprio nome pontua, trata-se de uma filosofia de ensino baseada no contato dos estudantes de medicina com a prática e a realidade da atuação médica, desde o início de sua formação, respeitando as características tanto da instituição (campo físico de tal experiência) como as peculiaridades do campo emocional dos estudantes e pacientes.

Desde o início, o principal objetivo do módulo foi a aproximação progressiva do estudante de medicina à prática médica. Isso permite que o estudante recém-chegado à Universidade possa conhecer os diversos cenários da prática médica na instituição e nos serviços externos a ela, bem como observar a realidade da medicina, por meio do campo de interação professores-estudantes, e também 
médico-paciente. Assim, a medicina idealizada é confrontada desde os primeiros momentos com a realidade da medicina vivenciada no hospital universitário e em outros cenários do Sistema Único de Saúde (sus).

Uma decorrência desse programa, que acabou se mostrando como objetivo geral, foi a integraçáo nos diversos níveis de conhecimento e experiência: biológico, psicológico e social, desde o início da formação médica, o que pôde auxiliar na internalização, pelo estudante, da concepçáo humanista da medicina. Secundariamente foi observado que a interdisciplinaridade do programa contribuiu para uma aproximação efetiva entre os vários docentes participantes.

\section{PROGRAMA}

O módulo inicia com a realizaçáo de um sociodrama, durante a semana do calouro, com o objetivo de levantar o perfil do estudante-calouro, suas expectativas, fantasias, medos e desejos. Essa atividade também aborda o papel do estudante ingressante do curso de Medicina e favorece a integração desse novo grupo no espaço físico da universidade.

O curso tem a duração aproximada de quatro meses, contando com quatro visitas a cenários, quatro discussóes e quatro reunióes entre docentes. Sua carga horária total é de 32 horas/aluno.

$\mathrm{Na}$ seqüência, durante o Io semestre do primeiro ano, os estudantes, em duplas, são oBSERVADOREs de vários cenários de prática médica em que se realizam atendimentos aos pacientes. É muito importante enfatizar que não há uma exposição "selvagem" do estudante às situações médicas, muito menos é exigida a realização de qualquer procedimento médico. Há professores designados previamente pelos serviços ou pela coordenação do curso para acompanhá-los. Caso uma situação se mostre mais difícil ou angustiante, como já ocorreu algumas vezes, 
os professores são responsáveis por acolher o estudante nesse momento e depois continuar a discussão com os grupos maiores.

Os cenários visitados pelos estudantes incluem:

a. Centros obstétricos: Hospital São Paulo - Hospital Vereador José Storopolli/Vila Maria, Hospital Pirajussara, Hospital de Diadema.

b. Unidades Básicas de Saúde (ubs) e Programa de Saúde da Família (psf): ubs Prof. Milton Santos, ubs Cupecê/Dr. Waldomiro Pregnolatto, ubs Americanópolis, ubs Dr. Geraldo da Silva Ferreira, ubs Vila Clara, psf/ubs Jd. Lourdes, ubs Aurélio Melloni/São Savério, ubs Maristela, ubs Parque Bristol, ubs Vila das Mercês, ubs Sacomã, ubs Jd. Seckler.

c. Hospital São Paulo I (urgências, enfermarias, UTI e centros cirúrgicos): ps Pediatria; ps Cirurgia, ps Clínica, Otorrinolaringologia/ Ambulatório, UTi Unidade Cardiologia/Enfermaria, Laboratório Clínico, Ambulatório de Genética Médica, Geriatria/Ambulatório.

d. Hospital São Paulo II (ambulatórios de especialidade, exames e laboratórios): Instituto de Oncologia Pediátrica IOP, Ressonância Magnética; Radiologia Vascular, Endoscopia Digestiva, Hematologia/Coagulação, Oftalmologia, Casa da Cirurgia de Mão, Casa da Cirurgia Plástica, Anestesia (incluso em 2007), Centro Cirúrgico, Laboratório de Liquor.

A observação é realizada por uma manhã ao mês, durante quatro horas. Na semana seguinte os estudantes, divididos em quatro turmas de trinta, encontram-se com os professores de seu grupo para discussão das experiências. $\mathrm{O}$ grupo de professores é sempre o mesmo nas quatro discussóes dos diferentes cenários, de modo que cada subgrupo mantenha o vínculo e o aprofundamento das discussóes.

Os professores para cada subgrupo são em número de cinco a oito, de especialidades diferentes: Clínica, Cirurgia, Ginecologia-Obstetrícia, Pediatria, Psicologia Médica, Medicina Preventiva e cadeiras básicas (Anatomia, Fisiologia, Bioquímica etc.). Há um terceiro mo- 


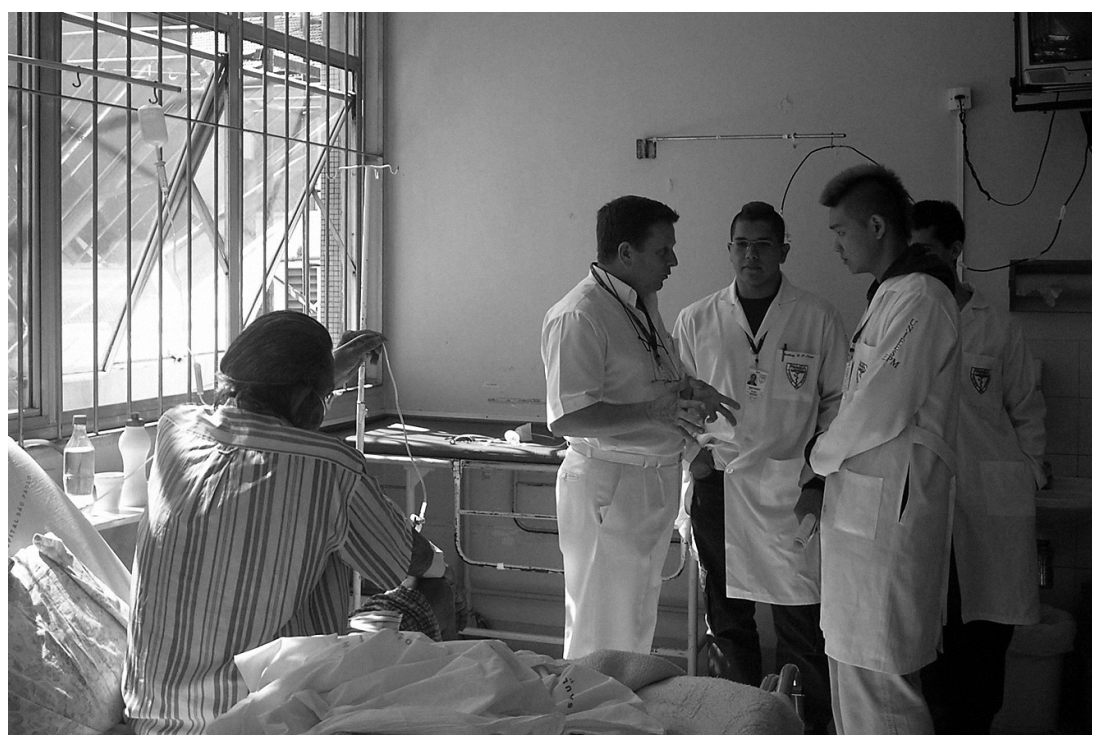

figura I. Pronto-socorro do Hospital São Paulo.

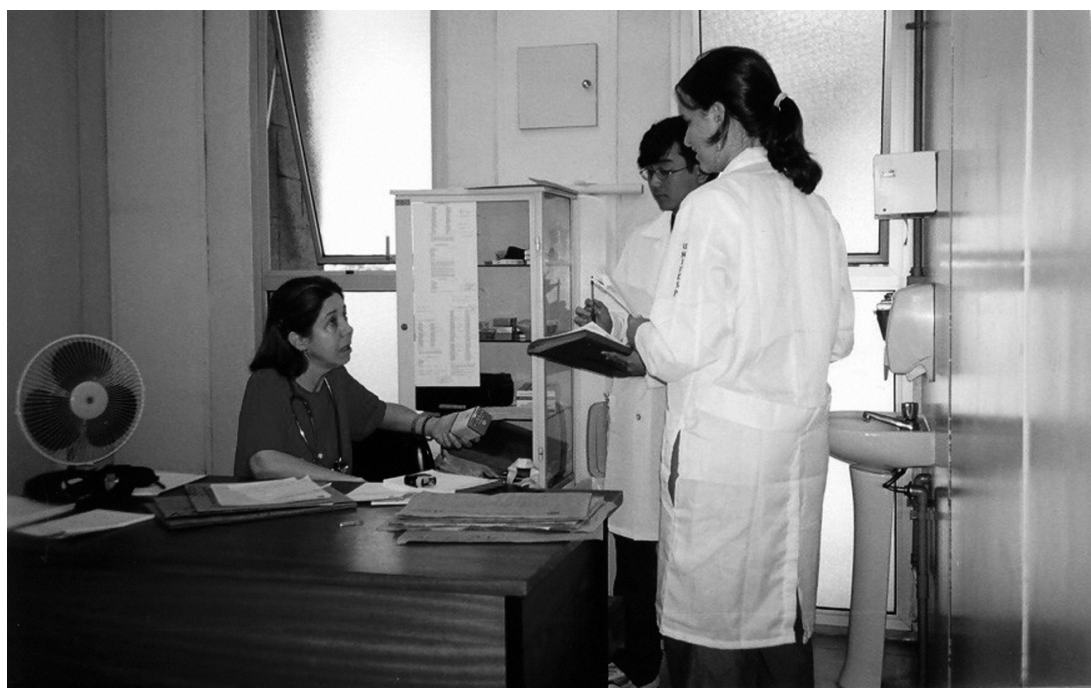

FIgura 2. Consulta médica em unidade básica de saúde. 


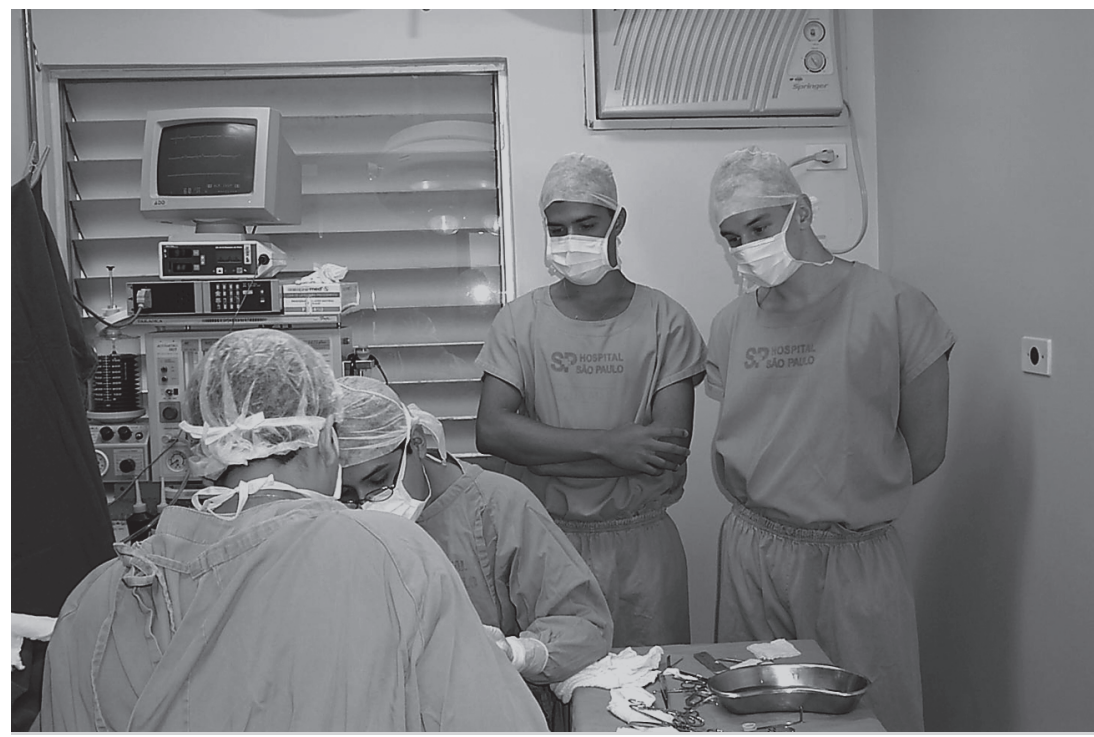

figura 3. Cirurgia na Casa da Mão, Departamento de Ortopedia.

mento de reunião aberta a todos os professores que participaram das discussóes e observaçóes com a finalidade de troca das experiências, homogeneização do aprendizado, elaboração do ensino e avaliação das atividades nos cenários e nas discussôes.

Por se tratar de atividade predominantemente grupal, julgamos sempre pertinente a utilização de um espaço físico onde não haja separação formal de docentes e discentes, diferente dos anfiteatros clássicos.

\section{A AVALIAÇÃO}

As avaliações são realizadas por relatórios escritos pelos estudantes, a cada observação e discussão. Em todos os relatórios é feita uma avaliação qualitativa (podendo ser identificadas unidades de contexto, unidades de registro e categorias de análise) e também é dada uma 
pontuação segundo a freqüência, desenvolvimento e conteúdo apresentado. O primeiro relatório é descritivo e pode receber uma pontuação máxima de cinco pontos (dois pontos pela freqüência e três pontos pelo desenvolvimento e conteúdo). O segundo relatório é reflexivo, também com pontuação máxima de cinco pontos (dois pontos pela freqüência e três pontos pelo desenvolvimento e conteúdo). No término do programa, procede-se a uma média final a partir dos quatro relatórios da observação e dos quatro relatórios da discussão.

O primeiro relatório deve ser realizado após a atividade de observação e é composto de duas partes: na primeira, o estudante descreve as suas impressóes quanto à estrutura do cenário visitado, atividades desenvolvidas, e, principalmente, suas consideraçóes a respeito de si mesmo, das relaçóes entre os profissionais de saúde, pacientes e acompanhantes. Na segunda parte, o estudante comenta a entrevista que realiza com um médico do cenário visitado, com ênfase na trajetória profissional e na capacidade de conciliação de interesses pessoais com os profissionais. Os relatórios seguem um modelo entregue previamente aos estudantes quando do início do curso.

O segundo relatório é realizado aos quarenta minutos finais do período de discussão. Os estudantes são estimulados a refletir e se expressar em grupo e individualmente, tanto na discussão como ao escrever o relatório.

Os relatórios, da observação (descritivo) e da discussão (reflexivo), são entregues para avaliação dos professores, os quais, após leitura, independentemente da sua formação profissional, tecem comentários a respeito do trabalho, que é devolvido para leitura do estudante, na discussão subseqüente.

A título de exemplo, apresentamos alguns trechos de unidades de contexto formuladas pelos estudantes:

[...] grande expectativa ao passar por cada porta e ver se as coisas eram realmente do jeito que eu imaginava ou assistia na televisão. Mas ao mesmo tempo 
estava sempre pensando se eu realmente conseguiria trabalhar num ambiente no qual teria que encarar diariamente o olhar de tanta gente desesperada.

[...] ao vivermos em um mundo carente de apoio social, o médico, nesse ponto da discussão, parece surgir como um Deus perante o paciente, e a situação não é essa.

[...] mas eu quis tentar quebrar essa visão idealizada de que o médico é um Deus e que ele pode tudo.

[...] parece que o profissional terá que ser super! Muito humano e superar tudo!... não devo... não devemos.

[...] há muitos casos específicos nos quais percebi que não existe um medicamento perfeito para solucionar a enfermidade.

[...] pude ver de perto a enorme confiança que eles depositam no médico.

[...] a minha expectativa é sempre a de poder ajudar a todos... porém, muitas vezes, essa expectativa vai além das minhas possibilidades, causando uma frustração.

[...] o clima geral no hospital é de medo e sofrimento, tanto dos pacientes quanto dos médicos.

[...] o principal medo que tive foi quanto ao envolvimento emocional em situaçóes de enfermidades agravadas pelas desigualdades no Brasil.

[...] situações como o controle de sentimentos são difíceis de serem contidas.

[...] o envolvimento com o doente levanta perguntas de análise complexa... podemos melhorá-lo?

[...] cada caso era discutido... esta equipe elaborava um diagnóstico... um processo longo e constrangedor para pacientes e familiares.

[...] houve um certo constrangimento de minha parte... comentar suas doenças com a professora diante deles... me deu uma terrível sensação de haver um abismo entre os enfermeiros e eu, pelas diferentes condições em que nos encontrávamos.

[...] a idade pode dificultar a comunicação... necessidade de preparo por parte do médico para entender e ser entendido.

[...] olhar o paciente como um todo, respeitá-lo, perceber que por trás de uma doença há uma pessoa e não um objeto. 
[...] este serviço... conta com profissionais nas mais diversas áreas... tudo para que o paciente consiga superar as dificuldades trazidas por uma doença.

A avaliação do curso é realizada no final do programa, verbalmente, e por meio de questionário padronizado. Ao final de cada módulo, além da avaliação oral feita pelos estudantes em seus próprios subgrupos e junto aos professores das discussóes, elaboramos um questionário composto por seis perguntas fechadas e um espaço aberto para sugestóes e críticas. Os estudantes não devem se identificar ao respondê-lo. As seis perguntas fechadas correspondem a terem atingido o objetivo do curso, aos cenários visitados, às discussóes e ao papel do professor. As respostas possíveis são: concordo inteiramente, concordo, às vezes, discordo e discordo inteiramente.

Seguem os gráficos em que comparamos os resultados em 2003 e 2004 .

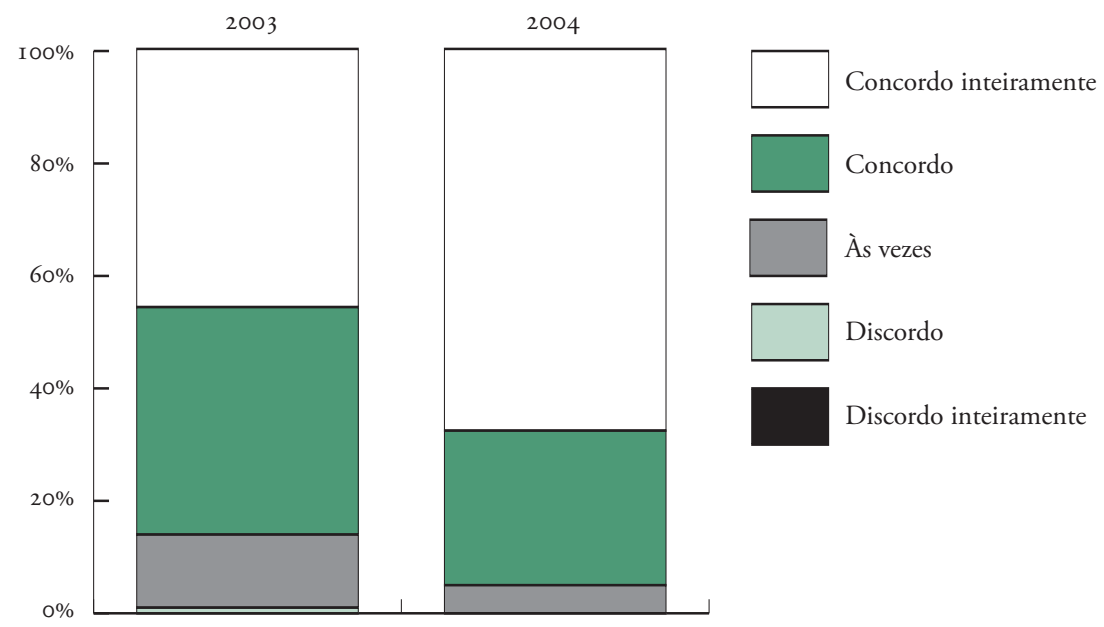

I. As atividades do módulo (momentos de observação e de discussão) possibilitaram uma aproximação à prática profissional do médico em diferentes cenários (centro obstétrico, PSF, UBS e hospital). 


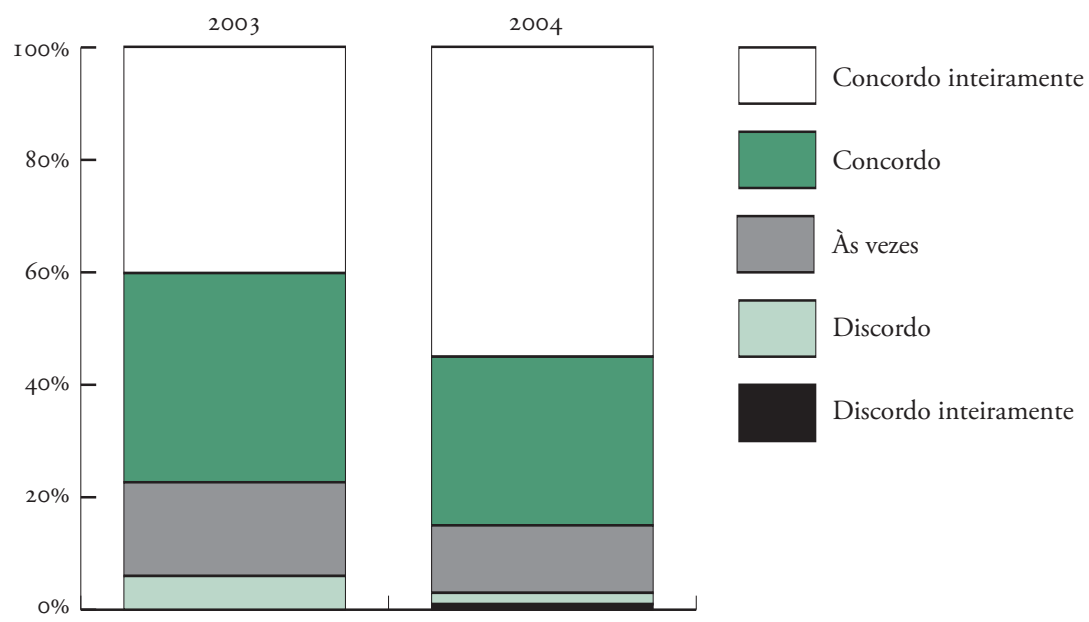

2. Os momentos de observação do PSF e UBS ofereceram subsídios para uma maior compreensão da prática profissional na atenção básica à saúde.

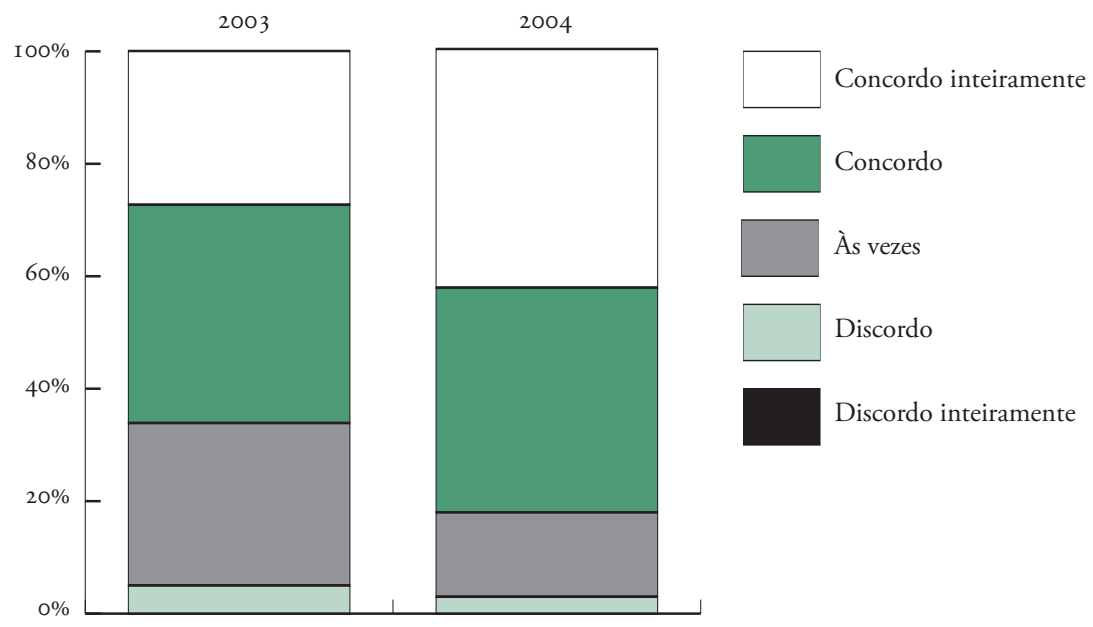

3. Os momentos de observação nos diferentes setores do hospital ofereceram subsídios para uma maior compreensão da prática profissional de maior complexidade e uso da tecnologia como recurso auxiliar a esta prática. 


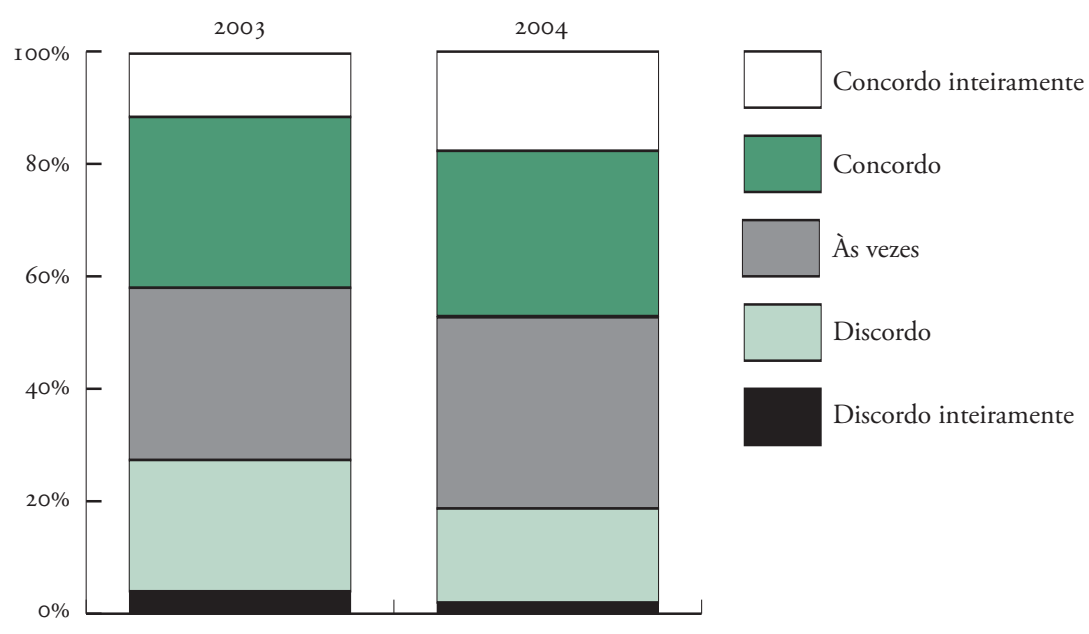

4. A organização dos momentos de observação, incluindo a recepção nos diferentes cenários, a disponibilidade dos médicos e as condições de infra-estrutura (transporte), mostrou-se adequada.

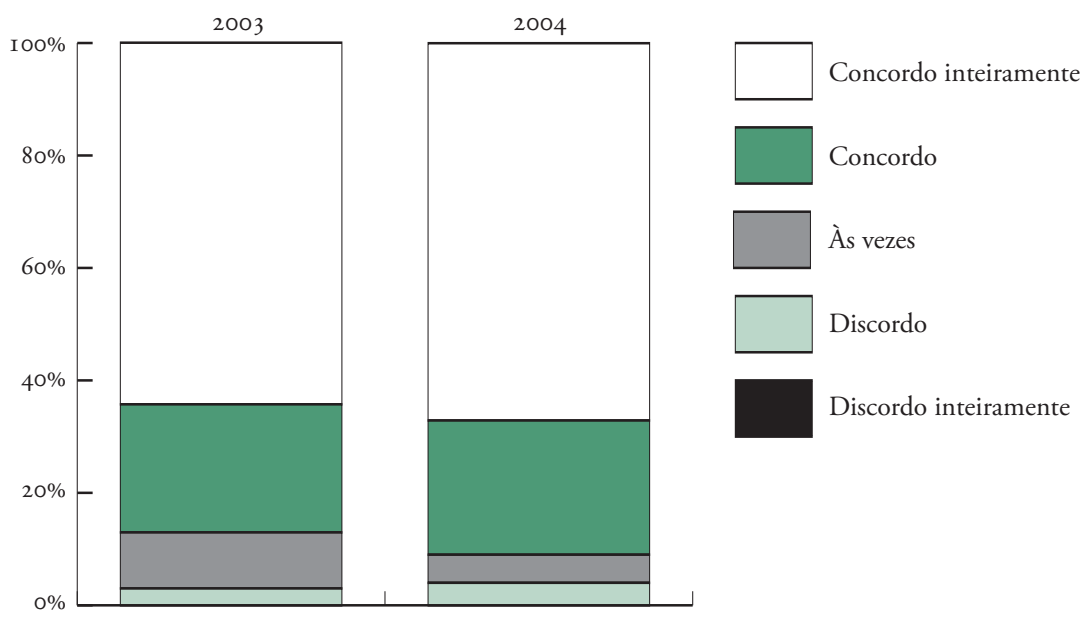

5. Os momentos de discussão propiciaram uma socialização do que foi registrado nos momentos de observaçáo, favorecendo trocas de experiências entre os alunos. 


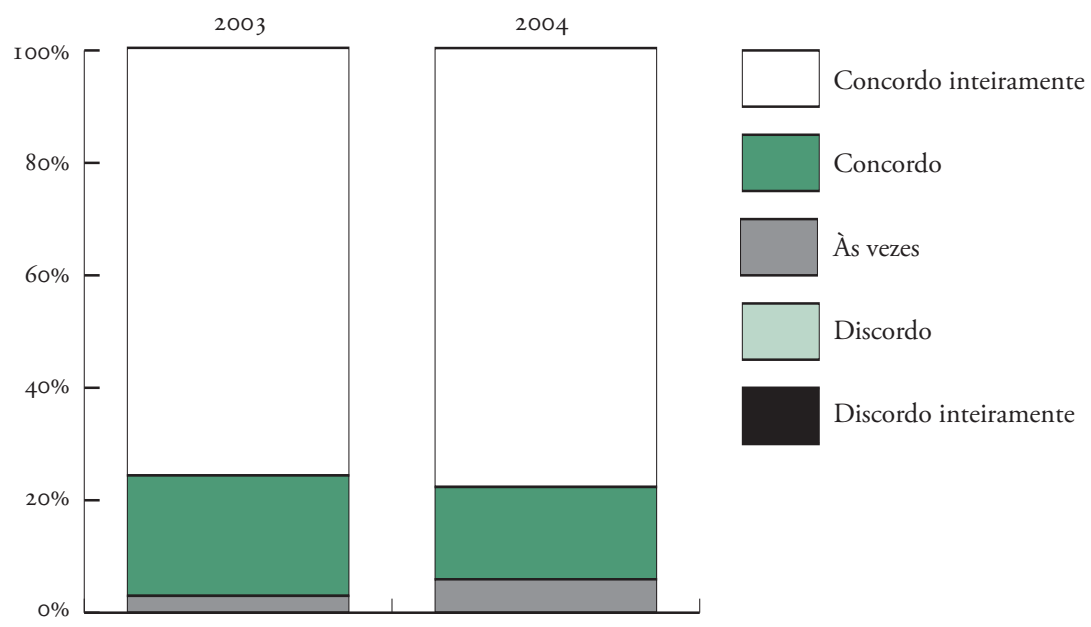

6. Os docentes, nos momentos de discussão, favoreceram e ampliaram o debate sobre a prática profissional do médico.

Podemos observar o aumento de adequação quanto aos objetivos do curso, bem como de satisfação dos estudantes. Chama a atenção o gráfico 5 sobre a discussão e o gráfico 6 referente à participação dos professores que mostra altíssimo grau de satisfação do estudante. Isto parece apontar para o valor do contato entre estudantes e professores neste momento em que estão chegando à faculdade e encontrando a pessoa do médico encarnada em seus professores de forma tão próxima e disponível. Pensamos que pode revelar também uma característica do verdadeiro professor, presente neste grupo de professores que integram o corpo docente deste módulo, ou seja, o educador, aquele que partilha da formação do futuro médico como pessoa.

\section{A IMPORTÂNCIA DO CORPO DOCENTE}

Um aspecto fundamental para o desenvolvimento do programa foi e continua sendo o engajamento do professor com a filosofia do curso e 
também com sua construção. Para tanto, o grupo de professores reúnese constantemente durante o período em que ocorre o módulo, como também após o seu término, no segundo semestre, constituindo-se num dos principais eixos integradores dessa tarefa educativa. Não é possível trabalhar com o estudante se o próprio professor não tiver espaço para elaborar o seu papel e sua tarefa. Essa prática tem trazido resultados animadores tanto para professores como para estudantes.

Para os professores, o módulo oferece a possibilidade de partilhar idéias com seus colegas de várias especialidades e de ciclos diferentes (básico: $\mathrm{I}^{\mathrm{O}}$ e $2^{\circ}$ ano, profissionalizante: $3^{\circ}$ e $4^{\circ}$ ano e Internato: $5^{\circ}$ e $6^{\circ}$ ano) num único momento, junto aos estudantes, permitindo que ele mesmo transite entre suas experiências como estudante, recorde sua trajetória na formação médica e venha a se constituir em um profissional com o qual o estudante possa se identificar.

Poder tolerar e dialogar com colegas cirurgiôes, clínicos, pediatras, psiquiatras, epidemiologistas, ortopedistas, pesquisadores e professores das chamadas cadeiras básicas, como anatomia, genética etc., configura na prática a medicina integrada, modelo que revela, por sua vez, a concepção do ser humano como um todo.

AS ADEQUAÇÓES DO MÓDULO NOS PRIMEIROS QUATRO ANOS

O curso vem se desenvolvendo com o mesmo formato básico, porém aprimorando a cada ano alguns pontos tais como:

\section{Cenários}

Escolha de novos cenários que tenham mais disponibilidade pessoal e funcional. No desenvolvimento do programa, no decorrer desses quatro anos, alguns critérios foram incorporados por se mostrarem importantes para a escolha dos cenários. 
A proposta da observação é de que esta seja realizada em um cenário do cotidiano, surpreendido sem modificaçôes, no entanto, não deve apresentar distorçóes da atividade profissional, refletindo modelos inadequados. O cenário deve proporcionar reflexóes construtivas que contribuam para enriquecer as discussōes e ampliar a visão de diferentes propostas de atendimento e relacionamentos.

Outro aspecto importante na definição do cenário é proporcionar diferentes ambientes com diferentes práticas. $\mathrm{O}$ contraste entre UBs, centros obstétricos, UTIs, centros cirúrgicos e consultórios, proporcionará diferentes modelos e níveis de complexidade, estimulando a discussão e apresentando ao estudante diferentes perspectivas de atuação na área, aproximando sua formação básica de sua formação prática futura, a partir de outros modelos além do "hospitalocêntrico".

Apesar de o corpo docente ser composto por profissionais das áreas básicas, clínicas e cirúrgicas, os cenários não incluem atividades nas áreas básicas, por apresentar como proposta práticas que envolvam a relação médico-paciente.

Nos cenários, a recepção dos estudantes é realizada por um professor comprometido com o programa, que apresenta a equipe e o serviço a ser observado e localiza o serviço no complexo Unifesp e no sus.

\section{Professores}

Com o fortalecimento da estruturação do grupo para as discussões, procura-se contemplar, no mesmo grupo, docentes dos departamentos e disciplinas de Psiquiatria, Psicologia Médica, Especialidades Clínicas, Saúde Coletiva, Cadeiras Básicas, Cirurgia e Obstetrícia. Um dos desafios atuais é promover a capacitação docente a partir de discussões regulares, formação em dinâmica de grupo e pesquisa educacional. 


\section{Estudantes}

Definir um programa institucional de transporte para os cenários localizados além do campus Vila Clementino-Unifesp e responsabilizar os estudantes por suas fichas de freqüência, que devem ser apresentadas no final de cada atividade para assinatura do docente e entregue no final do módulo.

\section{CONSIDERAÇÓES SOBRE PLANOS FUTUROS}

Um dos entendimentos sobre o módulo é que ele cumpre a função de receber e introduzir os estudantes ao seu novo ambiente dos próximos anos. Integra corpo docente e discente e guia os novos membros pela instituição. Trata-se quase que de um "ritual de iniciação educativo institucional". Tal função tem sido cumprida a rigor, e novos desafios surgem em uma universidade em expansão. $\mathrm{O}$ modelo aplicado ao Curso Médico já está sendo seguido no curso de enfermagem e tecnologia oftálmica, e julgamos que uma mescla de estudantes de diversas habilitaçóes pode dar um caráter mais universitário à aproximação.

Também a visita mista a cenários nos parece produtiva. Estudantes de Medicina, Fonoaudiologia, Enfermagem, Biomedicina etc., juntos, em cenários apropriados, devem propiciar visóes de pontos diversos e enriquecer o questionamento e o crescimento pessoal de cada indivíduo.

Vemos no grupo de docentes que se repete desde o início do módulo uma atitude proativa e enfática na manutenção do mesmo, apesar da imensa complexidade organizacional envolvida. São aproximadamente oitenta docentes e cinqüenta cenários. Vários deles encontram-se a mais de vinte quilômetros de distância do campus Vila Clementino, como algumas unidades básicas de saúde, o que demanda apoio institucional na locomoção dos grupos. 
Da atitude dos participantes surgiram solicitaçóes e atividades que reverteriam para uma maior visibilidade do curso, além de retribuição científica e didática para os docentes e discentes. Incentivamos trabalhos de iniciação científica com dados longitudinais colhidos ao longo de três anos do curso. Tal trabalho procura mapear modificaçóes pessoais e sociais dos estudantes ao passar pelo módulo. Também apontamos para a necessidade de publicaçóes, como este livro que hora se materializa, e de cursos de capacitação dos docentes, como dinâmicas de grupo e avaliaçóes, entre outros.

A busca ativa e constante de novos cenários e docentes é um desafio ainda maior para a manutenção do curso, assim como a busca ativa de docentes, a fim de ampliar e manter a multidisciplinaridade nas discussóes.

Com a preocupação da permanência do módulo, ora ativo devido ao entusiasmo de seus docentes, julgamos importante a elaboração de mecanismos que qualifiquem e quantifiquem a atividade didática. A consideração da carga horária do professor na graduação aponta para essa direção, regulamentando o tempo dedicado à prática do ensino, porém não nos parece ser mecanismo suficiente para o estímulo e o reconhecimento.

Por fim, cabe discutir e pontuar alguns objetivos implícitos no Programa de Incentivo às Mudanças Curriculares das Escolas Médicas, ou Promed, onde está inserido o módulo opM. Trata-se do estímulo à maior inserçâo da universidade no sus, e mais especificamente para o OPM, a aproximação do estudante das UBs. Para organizar essa aproximação em termos mais duradouros, colhemos os frutos de trabalho intenso da Unifesp que, juntamente com a Secretaria de Saúde do município de São Paulo, identificaram unidades básicas adequadas para a atuação universitária. Iniciamos a integração com tais cenários, tendo o cuidado de inserir um docente para cada grupo de estudantes nas visitas às UBs. Tais unidades devem receber estudantes de vários cursos, ratificando a multidisciplinaridade recém-comentada. 
Ao lado da prática na comunidade, entendemos que o cenário de prática médica da Unifesp é complexo e diversificado, com excelência em inúmeros laboratórios, ambulatórios, centros cirúrgicos etc., e privar o estudante desse contato não nos parece saudável. Para tanto, mantemos e dedicamos um extenso espaço do módulo para a visita a instalaçóes da própria Unifesp, no campus Vila Clementino.

\section{O SOCIODRAMA DESENVOLVIDO COM OS CALOUROS \\ NO INÍ́CIO DO CURSO}

Essa proposta foi construída nas reuniôes preparatórias deste módulo, quando foi sugerida uma pesquisa utilizando questionários, com o objetivo de conhecer o perfil desses alunos, suas expectativas e fantasias relativas à entrada no Curso Médico. Foi proposta então a utilização de metodologia psicodramática que permite atingir esses objetivos, além de facilitar a integração dos estudantes e propiciar um espaço para a criação de experiências coletivas que facilitem a expressão de desejos, medos, fantasias, valores, expectativas que permeiam o papel de aluno ingressante no curso de Medicina e o levantamento do perfil desses calouros.

O método que guia os trabalhos é o sociodrama, pertencente ao corpo teórico-metodológico da socionomia, criada por Jacob Levy Moreno (I889-I974).

Para Moreno o indivíduo é concebido e estudado através de suas relaçōes interpessoais. O Homem moreniano é um indivíduo social, porque nasce em sociedade e necessita dos outros para sobreviver, sendo apto para a convivência com os demais. Moreno criou a socionomia, ocupando-se do estudo das leis que regem o comportamento social e grupal ${ }^{\mathrm{I}}$.

I. C. S. Gonçalves, J. R. Wolff e W. C. Almeida. Liçōes de Psicodrama - Introdução ao Pensamento de J. L. Moreno. São Paulo, Ágora, I 988. 
A socionomia subdivide-se em: sociodinâmica, sociometria e sociatria. A sociodinâmica estuda a dinâmica das relaçóes interpessoais. Tem como método de estudo o role-playing, ou jogo de papéis, que permite ao indivíduo atuar dramaticamente em diversos papéis, desenvolvendo assim um papel espontâneo e criativo (papel profissional, papel familiar, papel de aluno etc.). A sociometria é o estudo da estrutura psicológica real da sociedade humana (parte visível e não visível). É a ciência da medida do relacionamento humano, o principal procedimento é o teste sociométrico. Na sociatria, que é o tratamento do social, os métodos são o psicodrama e o sociodrama, este é um tipo especial de terapia na qual o protagonista é sempre o grupo e os temas grupais, e as pessoas estão reunidas enquanto mantêm uma tarefa ou objetivo comum - estudar, trabalhar ou viver juntos...

O sociodrama tem sido realizado com a participação de um diretor $^{2}$, três/quatro egos-auxiliares (profissionais psicodramatistas ${ }^{3}$ ) e cerca de 120 calouros. Foram realizadas dramatizaçóes, imagens e atividades em pequenos grupos, trabalhadas e compartilhadas posteriormente com todo o grupo.

Como resultado desses sociodramas foi possível desvelar vários temas emergentes, dos quais destacamos: o papel de médico (transitando entre as funções de salvador/cuidador); o status que o papel de médico carrega como papel social (construído dentro da família, desenhando, muitas vezes, um conflito entre desejos da família versus talentos e desejos do sujeito e composto de histórias familiares e

2. Rudolf Wechsler, professor do Departamento de Pediatria da Unifesp/epm, psicodramatista.

3. Mariângela Pinto da Fonseca Wechsler (participou dos sociodramas de 2003-2007); Pedro D'Ávila Mascarenhas (participou dos sociodramas de 2003-2007); Maria Cezira Fantini Nogueira Martins (participou dos sociodramas de 2005-2007); Kelma Assunçấo Souza (participou do sociodrama de 2003); Maria Rita D’Angelo Seixas (participou do sociodrama de 2004); Fabio Könnigsberger (participou do sociodrama de 2007). 
pessoais relacionadas a adoecimentos, e/ou mortes; além da luta e sofrimentos para conseguir entrar no curso de Medicina e na "melhor” faculdade); expectativas quanto à vida universitária (experiência transformadora, rompimento com a adolescência; abertura para novas escolhas, novas experiências; pertencer a um grupo - unido, forte e duradouro, não se sentir excluído ou solitário); desejos referentes ao curso (conhecer muito sobre medicina; tornar-se um médico eficiente; conseguir respeitar as outras profissóes de saúde; lutar contra as injustiças, discriminaçóes, morte e dedicar-se muito ao curso).

O sociodrama revelou-se um recurso útil para a pesquisa (ao permitir o desvelamento de características do grupo), para a aproximação entre os alunos e para uma experiência ímpar de contato com os aspectos emocionais/coletivos ligados ao momento vivido e construído na inter-relação familiar-social e individual.

Como exemplo, descreveremos a seguir as diversas etapas do sociodrama realizado em março de 2007.

Iniciou-se com uma breve descrição do que é Psicodrama e Sociodrama e uma contextualização de sua inserção no módulo de Observação de práticas médicas e de seus principais objetivos.

Passou-se então para a fase de aquecimento inespecífico, que visa a ambientalização, ou seja, permitir que todos os participantes reconheçam o ambiente onde será realizado o trabalho - Salão da Atlética da Unifesp - percebendo seu volume, altura, distância, sons etc.; em seguida, a grupalização, com técnicas que favoreçam a transformação de agrupamento para o início de um grupo, preparando-os para um trabalho coletivo: foi solicitado que andassem no centro do saláo, em silêncio, percebendo seus corpos, suas sensaçóes e sentimentos naquele momento, para, em seguida, olharem uns para os outros nos olhos e iniciar uma comunicação não-verbal, expressando suas sensações e tentando captar as dos colegas; a partir daí, observar os colegas em seu todo, mirá-los, olhá-los de cima a baixo, de frente e por trás, depondo a vergonha, para em seguida se cumprimentarem com gestos, toques, 
respeitando-se e respeitando os limites dos outros. São exercícios para prestar atençáo em si e, ao mesmo tempo, nos outros tentando facilitar ao grupo o seu reconhecimento e achar caminhos para um trabalho conjunto de co-criação. É também objetivo prepará-los para $o$ papel de atores e autores, ou seja, o trabalho posterior que visa, através da co-construção no cenário dramático, por metáforas, revelar significados singulares do grupo.

Ainda nessa fase de aquecimento inespecífico passamos para outra fase, de nos conhecermos enquanto grupo, reconhecendo semelhanças e diferenças e tentando responder a pergunta: quem somos nós? De outro modo, podemos também dizer que é uma forma de investigação do grupo, servindo tanto ao grupo de calouros quanto ao de professores e para a equipe que dirige o trabalho, como um reconhecimento grupal dinâmico.

Solicitamos que o grupo continuasse a andar no centro do saláo e, segundo perguntas realizadas pelo diretor, o dividíamos em subgrupos:

- Local de nascimento, por regióes do Brasil: Nordeste (I estudante); Centro-Oeste (4 - todos de GO); Sul (2 - RGS e PR); Sudeste (4 MG, I ES, 3 litoral de SP, 3 GSP, 35 interior ESP, maioria do município de SP).

- Pais/familiares médicos: pai e/ou mãe e familiares não-médicos maioria; pai e/ou mãe médicos - menor subgrupo; outros familiares médicos - subgrupo um pouco maior que o anterior.

- Estado civil: casados, I; solteiros - maioria; namorando - cerca de metade; não-namorando - cerca de metade; com vontade de namorar - subgrupo discretamente maior; sem vontade de namorar no momento - subgrupo discretamente menor.

- Número de irmáos: filhos únicos - 5 (4⿳⺈⿴囗十一 subgrupo); I irmão(ã) subgrupo maior ( $\mathrm{I}^{\circ}$ subgrupo); 2 irmãos - médio/grande ( $2^{\circ}$ subgrupo); 3 irmãos -3 ( $3^{\circ}$ subgrupo); 4 irmãos -2 ( $5^{\circ}$ subgrupo); 5 irmãos - I ( $6^{\circ}$ subgrupo). 
- Anos de cursinho: (subgrupos semelhantes) entrou direto do colegial para faculdade $\left(3^{\circ}\right)$; I ano - maior subgrupo ( $\left.\mathrm{I}^{\mathrm{o}}\right) ; 2$ anos - subgrupo um pouco menor ( $\left.2^{\circ}\right)$; > 2 anos - menor subgrupo $\left(4^{\circ}\right)$ - máximo cinco anos (2).

- Preston elou curson outro curso superior: cursou e concluiu outro curso - 3 (esportes; física e administração) ( $3^{\circ}$ ); prestou el ou cursou, mas não concluiu (agronomia, farmácia, tecnologia em saneamento ambiental, engenharia química, engenharia de materiais, engenharia civil, engenharia de produçáo, biomedicina, fonoaudiologia, jornalismo) $\left(2^{\circ}\right)$; somente medicina maior subgrupo.

Em seguida solicitamos que todos encontrassem um lugar no salão e se acomodassem do melhor jeito, sentados ou deitados, para iniciar o aquecimento especifico, com o objetivo de aquecê-los para trazer à tona suas vivências desse momento de entrada no curso de Medicina da Unifesp, suas expectativas, anseios, fantasias, desejos, alegrias, temores, inseguranças, medos etc., solicitando para que, de olhos fechados, fizessem um relaxamento corporal, respiraçōes profundas e, mais relaxados, ainda com os olhos fechados, convidava-os a relembrar cenas/acontecimentos do:

- Passado: Quando pensaram/decidiram fazer medicina? Alguma cena marcante ou influência decisiva?

Solicitava-se que escolhessem a cena mais freqüente ou intensa, sem esforço (se não viesse, não tinha importância), e pudessem, ao escolher uma, percebê-la melhor, olhando para ela como espectador e percebendo detalhes: onde acontecia, quem eram os personagens dessa cena, o personagem principal, o contexto e o principal sentimento/ emoção (nomear) decorrente. $\mathrm{O}$ diretor solicitava que guardem essa cena e esses aspectos, que não os percam. 
- Presente: Quando e como souberam que entraram em medicina? Como e com quem foi a comemoraçáo? Como e com quem veio fazer a matrícula? Como foi a semana que antecedeu o início das aulas? Como foi vir para o primeiro dia de aulas? Como foi a participação no trote?

Escolher a cena, o personagem principal e o sentimento/emoção principal, registrar e guardar.

- Futuro: Pediu-se que se imaginassem no decorrer do Curso Médico: $\mathrm{I}^{\mathrm{O}}$ ano; $2^{\mathrm{O}}$ ano; $3^{\mathrm{O}}$ ano; $4^{\mathrm{O}}$ ano; $5^{\mathrm{O}}$ ano; $6^{\mathrm{O}}$ ano e na formatura...

Escolher a cena, o personagem principal e o sentimento/emoção principal, registrar e guardar. Dessas cenas das três épocas, passado, presente e futuro, escolher uma mais forte e/ou marcante: passado - subgrupo maior - cerca de cinqüenta; presente - cerca de trinta; futuro - cerca de vinte. Escolher um colega, formar um par e compartilhar essa cena escolhida.

Subdividir em cinco grupos: dois grupos do passado; um grupo do presente; um grupo do futuro. Subdividir cada um dos grupos em subgrupos (passado - em cinco subgrupos, presente - em dois e futuro - manter em um) - total de oito subgrupos com cerca de quinze participantes cada um. Compartilhar nos subgrupos, trocando suas cenas, destacando os personagens principais, o contexto e o principal sentimento/emoção.

Escolher uma história que possa representar o subgrupo, dar um nome para a cena escolhida pelo grupo, perceber qual foi a vibração, energia, emoção que motivou o grupo a escolher essa cena. Cada grupo escolhe um representante para apresentar o nome e um resumo da cena:

- Presente:

I. O momento de ter passado na faculdade, após muitos anos de cursinho, e este ano ter entrado em todas e ter escolhido 
a Unifesp... Foi seguido de um Tra-ca-trá (hino de guerra da Unifesp).

2. Nunca é tarde: Uma aluna que fez quatro anos em outra faculdade e decidiu que queria medicina.

- Passado:

3. Sinceridade delas - desafio: Duas amigas falam para um terceiro (atual aluno) que ele não iria conseguir passar, pois era muito difícil entrar em medicina, ele fez dois anos de cursinho, passou em várias faculdades de medicina e escolheu a Unifesp.

4. Impotência x Potência: Cena de emoção muito forte- mãe de uma aluna morreu quando ela tinha oito anos de idade e ela assistiu, predominando um grande sentimento de impotência, surgindo um desejo de transformar toda a impotência em potência; fazer algo pelas pessoas é muito importante!

5. A cura do câncer: Quando pequena os avós morreram de câncer e ela decidiu fazer medicina para descobrir a cura do câncer.

6. A perseverança: Fez cinco anos de cursinho junto com uma prima, esta prima entrou antes e ele continuou até passar.

7. Superação: Lembranças de fala do pai - Pai ameaça: "se não comer direito, vai ficar doente, vai ter que fazer um transplante" - começou a achar que estava doente, que ela fosse morrer, que a mãe também iria morrer e a partir daí pensou em fazer medicina para saber o que fazer num momento de urgência.

- Futuro:

8. A união faz o açúcar: Uma cena retratava que a uniáo durante os anos de medicina faria a força do grupo e os tornaria unidos. Seguido de outro Tra-ca-trá.

Foi feita uma escolha sociométrica, através de palmas, para a escolha de uma história. Duas foram as mais votadas: Impotência x Potência 
e $A$ união faz o açúcar. Perguntou-se aos dois grupos quem gostaria de representá-la (dramatizá-la). O primeiro grupo (Impotência x Potência) preferiu não representá-la, pois a protagonista estava muito emocionada, e o segundo grupo aceitou.

\section{Dramatização}

Solicitou-se ao representante do grupo que contasse a história novamente e ele descreveu: grupos grandes, como o nosso, tendem a formar "panelas", uns excluem os outros, alguns grupos são mais fáceis de incluir, outros mais difíceis se formam por semelhanças de idéias, sentimentos, preconceitos, afinidades... portanto, para o grupo náo se perder a meta é se unir. Pede-se para tentar mapear os personagens. Escolhem-se alunos em "panelas" - pedem-se voluntários para representar o papel de alunos em "panelas", outro personagem - o açúcar. Voluntários para representá-los e criação de um outro grupo de "personagens" - os ingredientes. Voluntários para representá-los.

No "palco dramático", espaço imaginário, definido no centro do salão, pede-se aos grupos de personagens - panelas, açúcar e ingredientes - que, um por vez, façam um movimento corporal para representá-los (analógico). Solicitam-se falas dos participantes dos grupos de "personagens" - falar alto o que está pensando, sentindo e/ou percebendo (solilóquios) - em seguida, solicita-se à platéia (todos os participantes que não estão em cena) que se expresse também, como se fossem desse grupo, com o olhar de fora.

Açúcar: imagem de pessoas sentadas no chão abraçando joelhos e fazendo um murmúrio que lembra um choro, um canto, um sussurro... Com os seguintes solilóquios: amizade, campeonato, união. A gente é um doce, sem mudar a conformação física, a gente dá grude, vitória, conquista, energia, atingir metas, união, coisa boa, gostosa, prazer, especial, o diferente. As diferenças podem provocar a união, não só a semelhança. 
Panela: pessoas agrupadas em pé, com vários movimentos, abraçando com braços ao redor dos ombros, às vezes o abraço se rompe e se reconstitui... às vezes de forma diferente, alguém tenta entrar e é barrado, tenta novamente e o grupo se une e se fortalece para impedir a entrada do "intruso", alguns são aceitos ou conseguem entrar... com as seguintes falas: preconceito com os de fora, a não-coletividade, exclusão, panela contra a porcada, inclusão, individualidade.

Ingredientes: amizade, solidariedade, respeito, união, tolerância, confiança, diferença...

O que a platéia está vendo, percebendo, o que chama a atenção?

Platéia em relação à panela: exclusão, fofoca, desprezo, prepotência; aos ingredientes: amor, consideração, atração, respeito, companheirismo, articulação, inclusão, força e diferenças; ao açúcar: ritmo, bebê chorão, loucura, alegria, lamentável, trote, solidão, grãos, açúcar amargo, compactos, autismo, individualidade, depressão, sem liga, grão seco. Grupo do açúcar cresceu, pessoas da platéia se agregam ao grupo.

Alguns comentários para/do grupo açúcar: pode ter espaço para ficar sozinho, todos são iguais, mas ninguém olha para ninguém no começo, quem está se sentindo amargo pode entrar no grupo? Foi convidado a entrar. Mais pessoas entram. O grupo começa a cantar: vem, vem, você também. Forma-se um grande grupo, sentados no chão, a partir do grupo açúcar e chamam um Tra-ca-trá.

Diretor lembra que continua existindo a panela, os ingredientes e o açúcar, e que poderíamos fazer uma interlocução entre esses grupos, consultando a sua equipe, considera que não é necessário e também por termos pouco tempo disponível.

Compartilhar: Trocar juntos, partilhar com. Aberto a todos:

[...] A música do açúcar nos cativou, fez-nos render.

[...] Fui os três. Na panela senti-me poderosa, fechada. Nos ingredientes me senti acolhida, podia ser diferente. No açúcar movimento solitário, difícil, 
depois com a participaçáa dos ingredientes, as pessoas foram entrando e me senti acolhida.

[...] Gostei da recepção. Por um momento, senti-me decepcionado, vi que a faculdade poderia não ser como esperava. A turma é muito gente boa, mas aconteceram algumas coisas que não gostou. $\mathrm{O}$ trote, mas depois dessa vivência acha que vai encontrar na turma a força e a união.

[...] Seis anos de curso. É muito tempo e é inevitável que alguém não goste de alguém, é melhor evitar briguinhas, afinal é a melhor faculdade de medicina.

[...] Nós somos diferentes, mas também temos coisas em comum, é difícil viver com as diferenças, mas é inevitável e importante aprender.

[...] Têm veteranos que recebem muito bem, alguns estáo sendo muito legais. Tem que ter respeito e náo fechar panela, quando formos do $6^{\circ}$ ano, eles serão RI e vão ensinar a gente.

[...] As panelas são inevitáveis, dos CDFs, da atlética, dos vícios, das meninas, do DCE etc. ... panelas vão existir, mas têm que ser fechadas?

[...] Nem sempre o cara é chato, tem a coisa da timidez, não isola o cara, às vezes ele tem dificuldade de fazer amizade, se não conseguir hoje, tem mais seis anos (palmas).

[...] Lembra da cena e diz: a panela fechada repercute no açúcar, ele fica sem liga, leva à solidão, dor, tem que buscar os desdobramentos e sair disso, com os ingredientes, tem que os deixar entrar, contagiar as panelas e transformar o açúcar.

[...] Se alguém se sentir humilhado, a intenção deles não era essa. Saí do trote todo sujo, rasgado. Ninguém queria sentar do meu lado no metrô.

[...] Queria contar que minha participação no açúcar no início não foi fácil, me senti ridículo. Depois veio a união. Mesmo assim não foi fácil, mas dos grãos separados, solitários, veio devagar a união. Estimulados pelas dificuldades que encontramos e querer superá-las e, se puder, com doçura fará com que seja um grande curso de medicina.

[...] Panela traz a falsa impressão de proteção, depois o açúcar atraiu, através de um blues (sua musicalidade). Pessoas podendo se juntar, juntando expectativas. É o começo de um grupo. 
Diretor: Um dos principais sentidos/objetivos da profissão médica é tentar reconhecer, acolher e aliviar o sofrimento dos outros, mas é importante também poder reconhecer, acolher e cuidar de seu próprio sofrimento. É importante, para si e para os outros, tentar acertar o ponto do açúcar, para náo "empapuçar" nem ficar sem gosto ou amargo, é buscar um equilíbrio, não ser impotente, nem onipotente, é a busca, construção da potência.

Solicitado para encerrar com uma palavra, antes de irmos embora, que represente o que foi vivido: açúcar, calor, família, tra-ca-trá, pessoal, turma 75, alívio, integração, conquista, amizade, alegria, acolhimento, desafio, grupo, mudanças, vocação, euforia, início, expectativa, encorajamento, tranqüilidade, sinceridade, consideração, cuidado para não virar panela, não se fechar, abertura, possibilidade, “com açúcar com afeto, fiz meu doce predileto para”... (canta a música do Chico Buarque), desafio e energia.

\section{A EQUIPE ENVOLVIDA NO MÓDULO \\ OBSERVAÇÃO DE PRÁTICAS MÉDICAS}

Desde 2003, muitos professores, profissionais da instituição, dos hospitais gerais e das uBs têm nos acompanhado e contribuído para o aprimoramento desta experiência. Seguem os nomes de alguns dos nossos colaboradores:

Adagmar Andriolo

Adaildes

Albert Lian

Alberto

Alexandre Bardomil Bortoletto

Alzira

Amélia

André Dias

Andréa Paula Andrade
Anelise Del Vecchio Gessullo

Ângela

Anis Gerbara

Antônio de Miranda

Antônio Sérgio Petrilli

Artur da Rocha Corrêa Fernandes

Beth Biari

Carlos Alberto Garcia Oliva

Carlos Alberto Mariano Maiorino 
Carlos Augusto Anadão

Carlos Edval Buchalla

Catarina Martins Sena

Cátia Maria Vieira Leite

César Uehara

Clóvis Eduardo Tadeu Gomes

Cristina

Daniel Almeida

David Shigueoka

Dayse Lourenço

Décio

Domingos Palma

Dulce Fonseca Soares Martins

Edson K. Cury

Edson Parise

Edson Stefanini

Eduardo Augusto Camarote

Eleonora Menicucci de Oliveira

Eliana Caran

Eliana Tiemi

Eliane C. Araújo

Eliane Teixeira de Almeida

Elza Maria Branco Padrão

Emilía Inoue Sato

Eurico Adonias Magoso

Fábio Monastero

Fausto Colla Cortesão Zuzarte

Flavia Regina Madalosso Kerr

Flávio Falloppa

Francisco Antônio de Castro Lacaz

Frida Zaladek Gil

Glaura Cesar Pedroso
Ideli Aparecida Marconi Pereira

Ilka Lopes Santoro

Ivanilda Argeneu Marques

Ivanir Ferreira Luz

Ivone M. Meimão

Jaime Passos Mota Silveira Filho

João Aléssio Juliano Perfeito

João Carlos Baptista

Jociane Negráo

José C. Baptista

José Donizete Rosolen

José Ernesto Ehrembery Fusco

José Roberto Ferraro

José Roberto Migliole

Josefina Aparecida Pellegrini Braga

Juliana Sallum

Julieta de Freitas Ramalho

Júlio de Ricardo de Souza Noto

Julio Elito

Julisa Chamorro

Kátia Nunes Cordeiro

Ladislau Glausivsz

Laércio Gomes Lourenço

Leda

Leodete de Oliveira Guerhardt

Ligia Mendes dos Santos Bonder

Lourdes

Lúcia Christina Iochida

Luciene Covolan

Lucy D’Alcântara Brabosa

Luís Garcia Alonso

Luiz Antônio Nogueira Martins 
Lygia Mendes dos Santos Border

Magda Takano Kushida

Márcia S. Grarinez

Márcio

Margaret Mitiano Gasques

Maria Kouyoumdjian

Maria Adelaide Avancine

Maria Antônia Machado

Maria Aparecida de Almeida Carvalho

Maria Cecília Hamagi

Maria Cristina Antunes Horta

Maria Del Carmem Janeiro Perez

Maria Inês Mokodsi

Maria Mirtes Figueiredo

Mariângela Cainelli de O Prado

Mari Lyse Moyses Silveira

Marina R. Joaquim

Marina Xavier

Mario Alfredo De Marco

Mary Chen Tseng

Maysa Seabra Cenderoglo

Meyer Izbicki

Milton Della Nina

Milton Scalabrin

Miriam Hinai

Miriam Matsumoto

Mirlene Cecília S. Cernach

Murilo Moura Sarno

Nacime Salomão Mansur

Nadia Aparecida Barbosa Moreno

Naoko Aristaka Paes

Nelson Sass
Newton de Barros Júnior

Nicanor Rodrigues Pinto

Nildo Alves Batista

Nivaldo Silva Corrêa Rocha

Oswaldo Shigueomi Beppu

Otávio Augusto Casagrande

Paulo Boschov

Paulo Schor

Paulo Spinola Costa

Regina Célia Lopes

Renata

Renato Moassabe Bruni

Ricardo Smicth

Rita de Cássia Gerab

Rita de Oliveira da Silva

Rosana Fiorini Puccini

Rosângela Ciongoli

Roseli Barros Grangel

Roseli Giudicci

Rosely

Rosemarie Andreazza

Rosiane Mattar

Rosinha Y. Matsubayaci Morishita

Rudolf Wechsler

Rufino Domingues Lopes

Sandra Aparecida Vieira

Sandra Beatriz Paranhos Medice

Sandra Oliveira de Campos

Sandra Regina P. S. Borges

Sandra Spedo

Sandro Luís de Andrade Matas

Sérgio Domingues 
Sérgio Y. Tiaen

Simone Maluf Gomes

Solange Martins Elias

Sônia Dias Freire Lanza

Stephan Geocze

Sue Yazaki Sun

Susume Ikeda
Terezinha Jesus Gomes

Tomika Hondo

Vânia Maria L. Bagagli

Vera Lucia Sdepanian

Vilmon de Freitas

Wilma Yoshie T. Bugliese 
